\title{
The Volta Dam May Help Wildlife in Ghana
}

\author{
By GEORGE CANSDALE
}

A new lake which will eventually cover 3,500 square miles, with a margin 4,500 miles long, is now being formed in Ghana with the damming of the Volta River. The dam was closed early last year. Though the lake has grown rather more rapidly than expected as a result of the fairly heavy rainy season in 1963, it is not expected to be full until after the rainy season of 1965 . In these extracts from a report on the effects the new lake is likely to have on the wildlife, Mr. Cansdale, who served fourteen years on the Gold Coast as Forest Officer, estimates that most mammals will be able to escape the rising waters without difficulty, and that the flooding may even be of benefit to the water chevrotain, hippopotamus, and the rare and still declining West African manatee.

T

THE areas of savanna forest that are being flooded in the Volta scheme are, in the main, those which have been accessible to villages and transport routes, so that the animals there are few in number anyway. Moreover, flooding is an almost annual occurrence, and the animals have experience of moving out of danger. The lake will rise slowly, making it easy for the ungulates to keep ahead of the water, and forming few temporary islands, while the permanent islands should be large enough for animals caught on them to be safe. So no rescue operations are likely to be needed.

The riverain forests of the Volta system, however, involving hundreds of square miles, will largely disappear, and tributaries other than the Oti and the Afram will be flooded back to where they leave the forest or become very narrow. Along the Afram River, which meanders along a broad valley, and where several large forest reserves will be submerged, the animals on the south bank will be driven back into the more or less adjacent high forest, which they can reach quite easily, and to the fauna of which they all belong. On the east bank of the Volta, as far north as the junction with the Asukawkaw, they can escape to the forests of the Togoland hills.

On the Afram Plains, between the Afram on the south and the Black Volta to the north, the patches of more or less closed forest which have developed on areas with deep soil, should provide adequate sanctuaries for the animals until a denser growth develops along the edge of the lake. The ungulates most affected are the bongo, the yellow-backed duiker, giant forest hog, and red river hog. Others are the black, bay, and Maxwell's duikers, the royal antelope, and the bushbuck.

The water chevrotain is still found in the less accessible riverain forests and should not be endangered by the flooding which may well make its habitat larger and safer. 


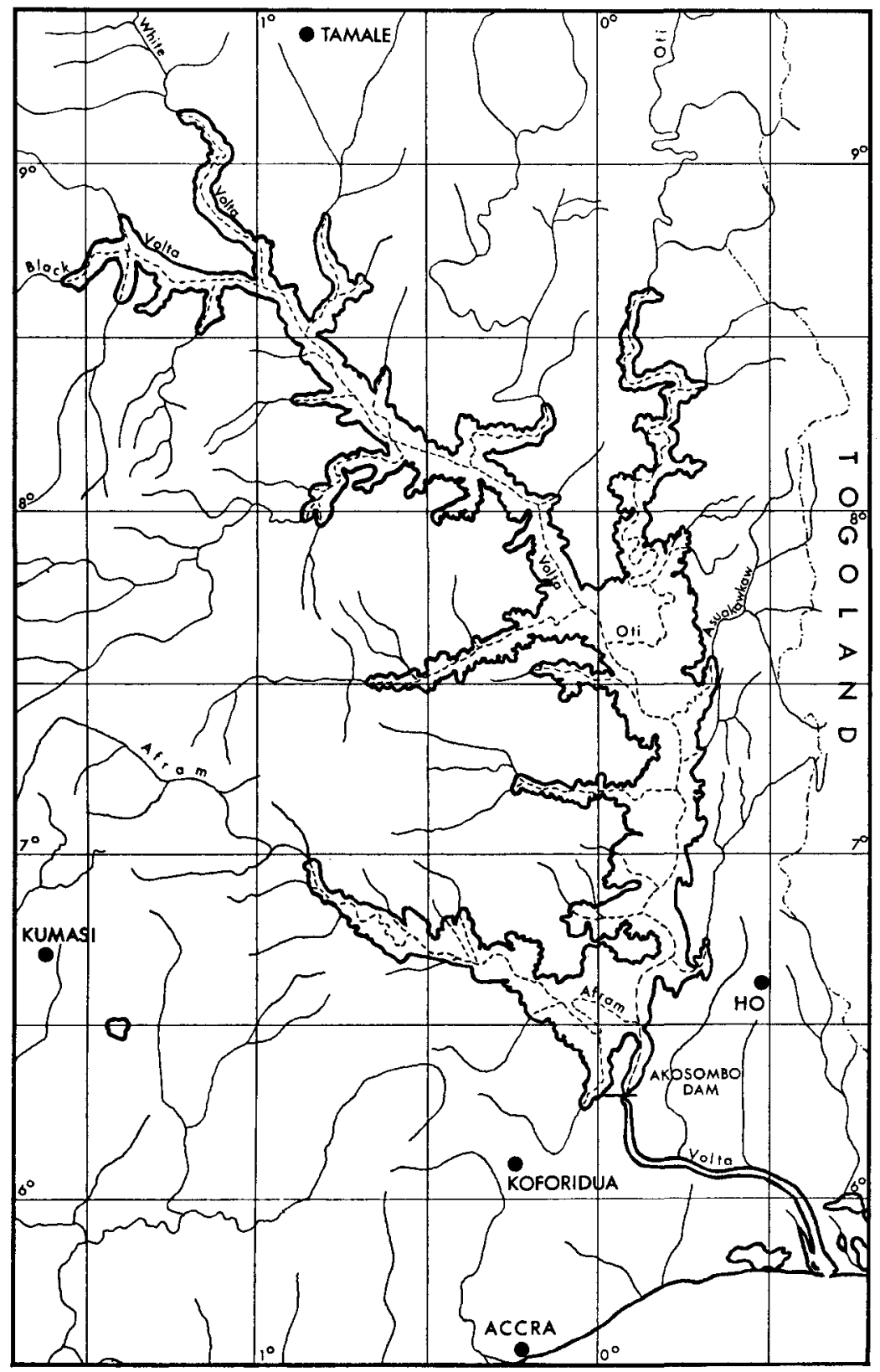

A map of Ghana, with the outline of the lake drawn in as it will be when full, showing the immense margin in relation to the total area. Photographs of the Afram Plains and the Afram River are on Plates 14 and 15, following page 188. 
The main arboreal species in the riverain forests are diana, putty-nose, and mona monkeys; black and probably olive colobus ; potto, blackbellied and tri-cusped pangolins; and about six species of squirrel. Those finding themselves on the east and south of the lake should be able to use the same escape routes as the larger mammals, although north of the Afram and west of the main Volta some may become marooned in the taller trees. It is doubtful whether the considerable expense of rescue operations for these could be justified.

The sequence of events in the first few years is difficult to forecast, in particular the results of killing so much vegetable matter. In the high temperatures breakdown should be rapid and it should not be long before fish take over. In temperate zones the large quantities of insects, worms, etc., made available by flooding allow rapid fish growth in the early years of a reservoir : this may or may not apply here.

Crocodiles are likely to increase, being already found more or less all over the area. Research in Central and East Africa has shown clearly that crocodiles are beneficial to a fishing industry. The very small crocodiles feed mostly on invertebrates such as dragonfly larvæ, giant water bugs and beetles which are serious predators of fish eggs and fry. As they grow bigger the crocodiles' main prey is fish, mostly predatory species, and they seldom take the much more desirable Tilapia which should form the basis of a large fishing industry. Older crocodiles take a number of aquatic birds and mammals which are more serious enemies of fish. Later it may be possible to harvest crocodiles in reasonable numbers.

Trees are likely to remain standing in the water for many years and to attract nesting colonies of birds such as egrets, darters, and cormorants, as happened on the Accra Plains when a dam was formed.

It is possible that the lake will form an ideal habitat for hippopotamus, which spend most of the day in water and range widely by night to graze on land. The effect of the rising water on the poor land around the new margin is hard to predict but it should encourage the growth of suitable grazing for hippos over many square miles, while most of this margin should be easily accessible to water deep enough for their comfort and safety by day. The annual variation in the height of water is unlikely to exceed 10 feet and the seasonal fluctuation should be less than this.

\section{Need to Protect the Hippos}

There are not many hippos in the area, and it is just possible that all have been killed out, though they are still found in several higher reaches of the Volta system. On paper the hippopotamus is already fully protected, but so far this protection has not been enforced, and it is absolutely essential to give the hippos complete safety for at least five years if stocks are to be built up. In time the population could be such as to allow several hundred a year to be culled for meat. Their presence in large numbers is also beneficial to the production of edible fish, through the fertilisation of the water by their fæces and the subsequent growth of algæ.

The Volta system may be the only part of Ghana suitable for the manatee; at any rate its existence in other large rivers has never been confirmed. It is probably extinct in the reaches below the dam, but recent 
evidence suggests that it is still found in the Kete Krachi area and that it is still the subject of ritual hunting. The flooding may very well increase its habitat in West Africa, but it is presumed to feed on aquatic plants and on vegetation growing on or overhanging the banks. It would eat vegetation that no other animals would convert into edible animal protein, and it might help in controlling aquatic plants, as it does in British Guiana. In theory only it is already fully protected. There is every reason to enforce this protection rigidly if there is to be any hope of building up a sufficient stock to allow controlled cropping later.

The Oti River Valley, about the fauna of which little is known, will form a large north-east arm of the lake. The river meanders through grassland, some of it marshy, and there are few people. A report that the marshbuck, or sitatunga, is here could well be true; it would be the first record for Ghana of this specialized member of the bushbuck family, though it is well known in the coastal regions of Nigeria and near Lake Chad. The terrain makes detailed reconnaissance difficult, nor would trapping and rescue operations be feasible in a sitatunga's habitat, but in this gently undulating valley country several extensive flat islands will be left. These should at least serve as a temporary sanctuary for any sitatunga, even though the present marsh habitat completely disappears, and it is possible that some parts of these islands will in time become swampy and covered with a wetter type of vegetation.

\section{Guide to South African Wildlife}

During recent years there have been several useful handbooks on African wildlife, but one of the main gaps has been where least expected, in South Africa. The Game Animals of Southern Africa, by C. T. Astley Maberley, Nelson, 18s. $6 \mathrm{~d}$. fills it in a most comprehensive manner, and moreover does a great service by gathering together so much valuable data. The assembled biological notes of many species make fascinating reading, and for the most part they are commendably accurate. Of course there is the occasional slip, and a few avoidable gaps in the recorded knowledge both of habits and ranges. It is a pity also to have emphasized the sores so commonly seen in the black rhinoceros, when it has long been established that they are merely a form of dermatitis.

The book will admirably serve its stated purpose, of providing a most useful guide for all visitors to South Africa and its parks and reserves, but because it will also be much used by those who are closely interested in the study of mammals, two things are unfortunate and one of them also tiresome. The first, that in scientific terminology the author does not follow up-to-date check lists ; the second that there is no index of either trivial or scientific names. The title also could have been improved: whatever the connotation of "game animals", the term is one to be avoided and surely can never be referable to hyenas, mongooses, jackals, and monkeys ?

The author has an enviable reputation for the skill and attractiveness of his wildlife sketches. With very few exceptions, among animals with which he has not been too familiar, they evidence all those details which characterize a truly observant field naturalist. 'Indubitably the book will have a wide circulation and indeed deserves it. 